\title{
Utilization of the finite element method for the calculation and examination of underground power cable ampacity
}

\author{
Mahmood Khalid Hadi \\ Department of Biomedical Engineering, Faculty of Engineering, Kerbala University, Kerbala, Iraq
}

\begin{tabular}{ll}
\hline \hline Article Info & ABSTRACT \\
\cline { 2 - 3 } Article history: & $\begin{array}{l}\text { Currently, the use of underground electric cables is a regular feature of } \\
\text { present-day power transmission and distribution schemes. Issues related to } \\
\text { economical limitations and the lack of adequate space led to the need for } \\
\text { Received Jan 16, } 2019 \\
\text { cables with an elevated current carrying capacity (ampacity). In order to } \\
\text { achieve this objective, public services around the globe are focusing not only } \\
\text { on better designs, but also on improving the level of precision in the context } \\
\text { of cable parameter values. Precise parameter values are essential for ensuring } \\
\text { that the replicated outcomes correspond sufficiently close to actual } \\
\text { circumstances. While the conventional approach to ampacity calculation is } \\
\text { through the IEC-60287 procedure, the numerical route is considered more } \\
\text { specific and flexible. This endeavour harnesses the finite element method to } \\
\text { conceive an innovative process for calculating the thermal field and ampacity } \\
\text { of a cable. This process involves the crafting of a temperature field } \\
\text { distribution model for scrutinizing temperature distribution in the region of } \\
\text { an electric cable, and the deployment of the linear interpolation procedure for } \\
\text { computing its ampacity. Subsequent to its formation, the model was put into } \\
\text { operation on the underground cable 33KV XLPE. }\end{array}$ \\
Ampacity & IEC standard
\end{tabular}

Copyright $@ 2019$ Institute of Advanced Engineering and Science. All rights reserved.

\section{Corresponding Author:}

Mahmood Khalid Hadi,

Departement of Biomedical Engineering,

Kerbala University,

Karbala province, Iraq.

Email: mhm_mhm_80@yahoo.com

\section{INTRODUCTION}

As mentioned earlier, the use of underground power cables has been established as a common aspect in schemes related to the transmission and distribution of power. In the face of problematical laying conditions, the ability to quickly and precisely ascertain the current carrying capacity of a cable has come to be recognized as crucial [1-3].

The current-carrying capacity of a cable can be computed by way of two procedures: the IEC-60287-based thermal analysis method, and the numerical calculation method. The emphasis of the IEC-60287-based thermal analysis method is on the physical location and climatic circumstances of the site earmarked for laying. While this one-dimensional model simplifies the computation process, the rectification aspects cannot be easily ascertained through testing. This circumstance renders the occurrence of certain inaccuracies unavoidable [4]. The numerical calculation method, on the other hand, adopts the finite temperature field theory to analyse the temperature dissemination of a cable and its laying site. Due to its emphasis on real-life settings, this method has proven to be superior as the results attained tend to be more precise. Currently, numerical approaches that include the boundary element method, the finite difference method, the finite volume method and the finite element method are held in high esteem. However, the employment of the first three methods for the laying of underground cables is hampered by unavoidable and 
challenging issues related to boundary conditions. In view of this, the finite element method is a better option as it comes with the capacity to randomly organize the grid nodes [5-11].

Taking the above conditions into consideration, we fashioned a temperature field distribution model for investigating the temperature dissemination of electric cables. This model, which is managed by ANSYS software, is guided by the heat transference principle and the finite element method. The developed model considers the laying situation and the changeable external setting to revise its parameters accordingly to accommodate any variations. This ensures a more precise current carrying capacity reading. Of the three standardized ampacity ratings, i.e. steady state, transient (also known as emergency) and short-circuit ratings, this study opted to focus solely on the steady state ampacity ratings.

\section{RESEARCH METHOD}

The configuration of the case study, which is represented by a three-phase circuit comprising three single-core cables $(33 \mathrm{kV})$ buried directly in local soil, can be observed in Figure 1. The distance between the two neighbouring phases is $0.4 \mathrm{~m}$, the burial depth is $1 \mathrm{~m}$, and the air temperature was recorded as $400 \mathrm{C}$. As the cables are loaded at $1160 \mathrm{~A}$, the ceiling temperature of any conductor is pre-set at 900C. Elements that can have an impact on cable capacity (including exterior heat sources, the laying method and the removal of moisture) are carefully considered and alterations are carried out in accordance to the circumstances. Figure 2 provides particulars on the structure of the cable.

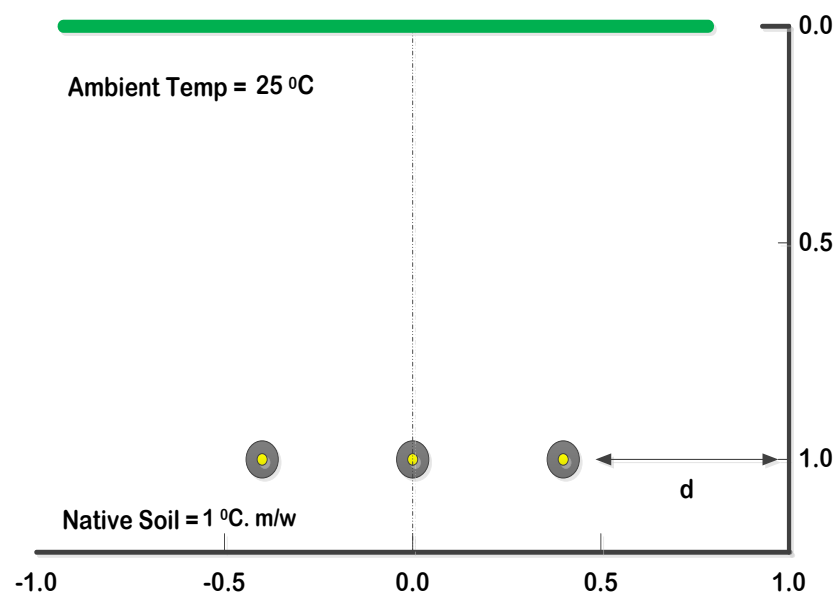

Figure 1. Configuration of the case study

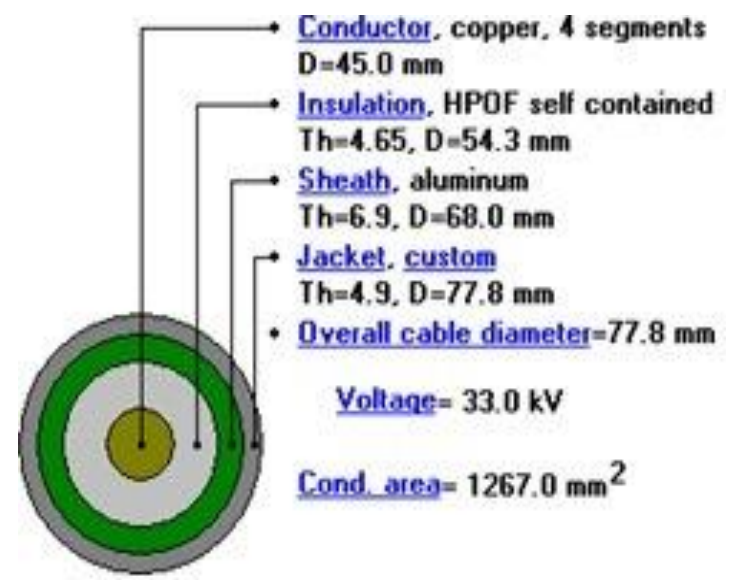

Figure 2. Particulars on the $33-\mathrm{kV}$ single-core cable structure 


\subsection{Computation for losses}

According to the IEC standard [12-14], the heat sources in a cable develop from losses taking place in three areas of the cable. These are joule losses occurring in the conductor, dielectric losses, and sheath loss attributed to induced currents. Joule loss, which is attributed to the resistance of the conductor, is expressed as:

$$
W_{c}=I^{2} \cdot R_{a c}
$$

whereby WC signifies joule loss for each unit length, I (ampere) signifies current, while Rac signifies ac resistance for each unit length.

Sheath loss is caused by shortfalls in the sheath or screen as a result of circulating currents $\left(\lambda 1^{\prime}\right)$ as well as eddy currents $\left(\lambda 1^{\prime \prime}\right)$. This loss is expressed as:

$$
\lambda_{1}=\lambda_{1}^{\prime}+\lambda_{2}^{\prime \prime}(2)
$$

In the IEC standard, a multiplier is utilized to compute sheath loss as a function of the joule loss. Dielectric losses are attributed to charge seepage and the consequences of hysteresis in the dielectric. This can be put across as:

$$
W_{d}=W C_{d} U_{0}^{2} \tan \delta
$$

where $\mathrm{Wd}(\mathrm{W} / \mathrm{m})$ denotes the dielectric loss of cable insulation, $\omega=2 \pi f$ in which $\mathrm{f}$ denotes the system frequency, $U o(V)$ denotes the voltage to earth, $\tan \delta$ denotes the loss factor of the insulation at power frequency and working temperature, and $\mathrm{Cd}(\mathrm{F} / \mathrm{m})$ denotes the insulation capacitance which can be conveyed as:

$$
C_{d}=\frac{\varepsilon}{18 \ln \left(\frac{D_{i}}{D_{c}}\right)} * 10^{-9}
$$

in which $\varepsilon$ represents the relative permittivity of the insulation, $D i(\mathrm{~mm})$ represents its exterior diameter, and $D c(\mathrm{~mm})$ represents the diameter of the conductor inclusive of the screen.

\subsection{The boundary conditions}

Irrespective of the technique employed to solve heat transfer problems, the establishment of clear cut boundary conditions is essential for the realization of a satisfactory outcome. For the most part, boundary conditions can be separated into three groups. For the first group, $T$ is stipulated on the boundary for $\mathrm{t}$ greater than 0 . For the second group, the offshoot of $T$ normal to the boundary is stipulated on the boundary for $t$ greater than 0 . And for the third group, an offshoot of $T$ in a route normal to the boundary is comparative to the temperature disparity with regard to the ambient environment on that boundary. This situation is liable to crop up at the boundary during the occurrence of convection. The equivalent control equations are presided over by the following (5-7) [16].

$$
\begin{aligned}
& T(x, y)|t=f(x, y)| t \\
& \lambda \frac{\partial T}{\partial n} \mid t=-Q_{2} \\
& -\lambda \frac{\partial T}{\partial n}\left|t=\alpha\left(T-T_{f}\right)\right| t
\end{aligned}
$$

Where, in Q2 indicates the density of heat flow rate, $T f$ indicates the fluid temperature, while $t$ and $\alpha$ correspondingly indicate the integral boundary and heat transfer coefficient.

In a commonplace situation, as the cable horizontal temperature gradient is 0 , the right and left edges of the buried cables (Figure 1) fit into the second boundary condition group. While the upper boundary neighbouring the ambient environment fits into the third boundary condition group (convective boundary), the lower boundary neighbouring the base can be slotted into the first boundary condition group. In accordance to the heat transfer theory, the distance $d$ can be computed in the following manner [15].

$$
d=r e^{2 \pi \lambda R}
$$


$R=\frac{\Delta T}{Q}$

whereby $Q$ specifies heat flow, $R$ specifies thermal resistance, and $\Delta T$ specifies the temperature descents of various dielectrics.

\subsection{Description of the finite element method}

In both the IEC and the IEEE standards, the air temperature factor is considered decisive during efforts to ascertain ampacity. This is particularly so when it comes to air cables. In view of the fact that the linear interpolation procedure comes with a computation process that is uncomplicated, quick and relatively precise, it was favoured by this study to compute the current carrying capacity through (10):

$$
I=\frac{\left(T_{k+1}-T\right) I_{k}+\left(T-T_{k}\right) I_{k+1}}{\left(T_{k+1}-T_{k}\right)}
$$

The hypothetical approach for the algorithm is as follows:

- Suppose a current value $I_{1}$ and follow up with a computation of the equivalent cable core temperature $T_{l}$. If $T_{l}$ is equal to the cable operating temperature $T, I_{l}$ is deemed the cable current carrying capacity. If $T_{l}$ is not equal to $T$, then redirect to step 2 .

- If $T_{l}$ slighter than $T, I_{l}$ will be enhanced by $4 \%$ and allocated to $I_{2}$. If $T_{l}$ is greater than $T, I_{l}$ will be reduced by $4 \%$ and allocated to $I_{2}$. Subsequently, calculate the equivalent cable core temperature $T_{1}$. If $T_{2}$ is equal to $T, I_{2}$ is deemed the cable current carrying capacity. If $T_{2}$ is not equal to $T$, then move on to step 3.

- In keeping with the procedure in step 2, the current value is computed repeatedly until it arrives at the cable core temperature $\mathrm{T}_{\mathrm{k}},<\mathrm{T}, \mathrm{T}_{\mathrm{k}+1}>\mathrm{T}$.

- Introducing $\mathrm{I}_{\mathrm{k}}, \mathrm{I}_{\mathrm{k}+1}, \mathrm{~T}_{\mathrm{k}}, \mathrm{T}_{\mathrm{k}+1}$ into formula 10 leads to the computed result I denoting the ampacity.

\section{ANALYSIS MODEL}

\subsection{Temperature dissemination in the vicinity of the underground cable}

The cable loss parameters were computed in line with the IEC-60287. These parameters, together with the theory of linear interpolation paved the way towards the computation of the current-carrying capacity of the cable which was revealed to be 1160A. Consequently, the temperature distribution at the site of the cable was also acquired. From the results exhibited in Figure 3, it can be surmised that the length of the upper and lower boundaries is the abscissa, while the length of the right and left boundaries is represented by the ordinate.

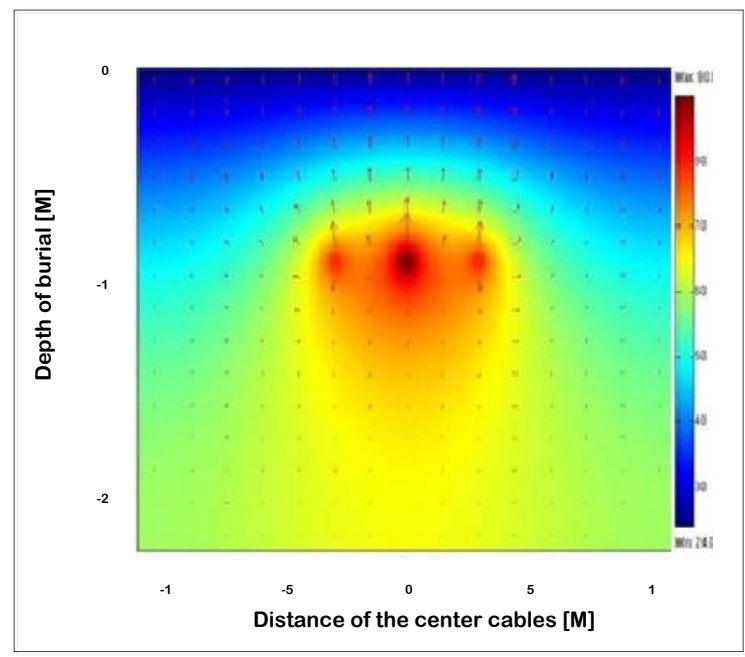

Figure 3. Temperature field distribution in the vicinity of the cable 
The cable temperature field distribution displayed in Figure 3 reveals that the rectangular area of the cables was considerably influenced. Hence, due to the removal of moisture from the soil, the corresponding thermal resistance was lesser. The thermal conductivity value of this soil area was recorded as $0.4 \mathrm{~W} /\left({ }^{0} \mathrm{C} . \mathrm{m}\right)$, while that of the other areas was recorded as $1.0 \mathrm{~W} /\left({ }^{0} \mathrm{C} . \mathrm{m}\right)$. As illustrated in Figure $4(\mathrm{a})$, by tracing the isothermal contour according to the critical temperature, the outline of the dry region can be established.

As portrayed in Figure 4(b), heat flux, which is generated by buried cables, plays a significant role in ascertaining the period for the development of a dry zone. This is very much in line with the study conducted by F. Donazzi et al. [16, 17]. Significantly, the simulation process revealed that the critical temperature as well as the ratio of the dry to wet thermal resistivity (or conductivity) is not influenced by heat flux emanating from the cables. This could be compatible with the viewpoint of Hartley and Black [18] which indicates that heat flux on the exterior of the cable has a significant bearing on the period for soil instability to set in. It is worth mentioning that while the IEC forwards the critical temperature for damp soils as $500 \mathrm{C}$, this study is of the opinion that it is closer to $550 \mathrm{C}$.

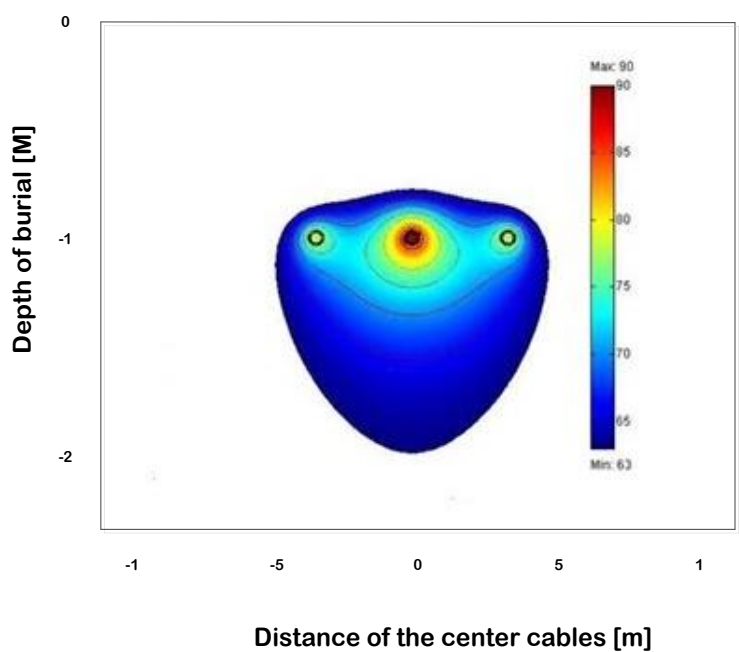

Figure 4 (a). Shape of the dry zone surrounding three single-core cables $(33 \mathrm{kV})$ laid directly in local soil

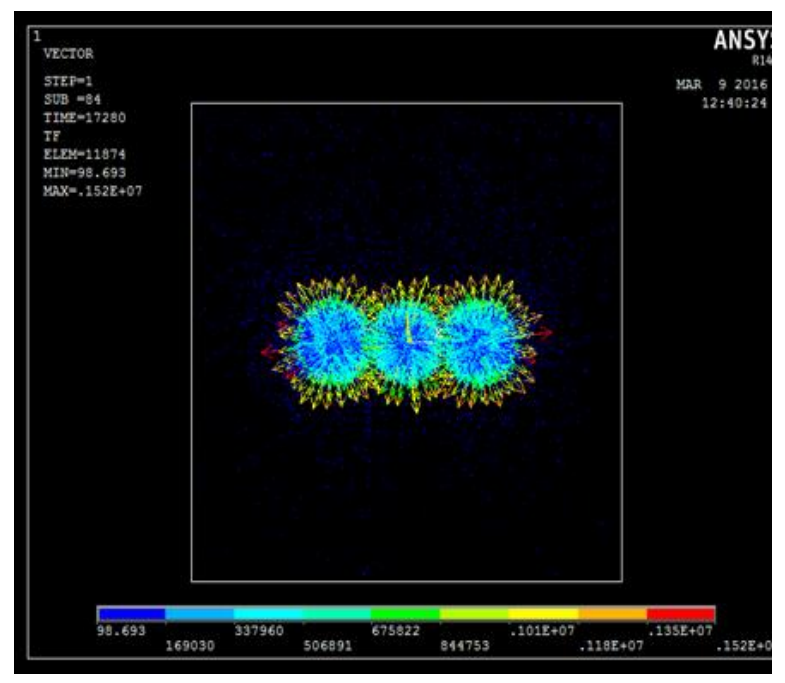

Figure 4 (b). Dry case arising from the generation of heat flux density at the cables

Figure 4. (a) Shape of the dry zone surrounding three single-core cables (33 kV) laid directly in local soil, (b)

Dry case arising from the generation of heat flux density at the cables

\section{AN EXAMINATION OF THE FACTORS INFLUENCING AMPACITY}

The underground cable installation parameters of soil thermal conductivity, air pressure and burial depth were varied in order to determine their impact on the current carrying capacity of the $33 \mathrm{kV}$ three single-core cables. The results attained can be observed in Figures 5, 6 and 7. The method leads to use numerical technical to obtain high accurate results. Making a cable operates in service for long period of time considering massive economy to investment costs. Unexpected cable failure because of harsh environment impact may cost utility large financial losses as well as the customer. This may contribute to solve these somewhat antithetical but highly relevant issues).

\subsection{The impact of the soil thermal resistance on ampacity}

Soil thermal resistance exerts a significant and direct influence on the heat dissipation factor. The elevation of temperature in soil surrounding the cable leads to the removal of moisture and a drastic decrease in thermal resistance. This circumstance results in a deterioration of the cable's capability to dispel heat. This phenomenon makes it challenging for the design engineer to decide how to account for the drying effect in cable ampacity calculations. As a consequence, the cable current carrying capacity is significantly decreased. Figure 5 illustrates the influence of soil thermal resistance on ampacity. As anticipated, the ampacity of the cable rose in tandem with the elevation in soil thermal resistance. In this work, it was also taken into consideration how the shape of the excavated area and the positioning of the cable in the excavated. 


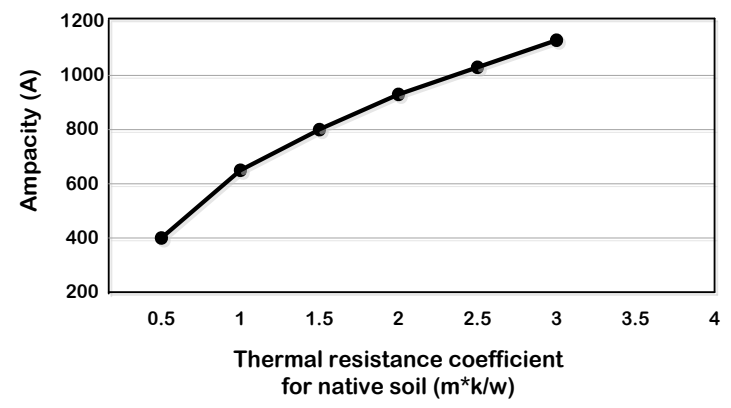

Figure 5. The relationship between ampacity and soil thermal resistance

\subsection{Investigation on the influence of ambient temperature}

Ambient temperature, which mostly applies to the temperature of the medium surrounding a cable, also has a profound influence on ampacity. This is particularly so for underground cables. With a substantial rise in air temperature, the heat convection capacity of soil and air declines. As a result, the heat dissipation capability of the cable is reduced and this leads to a deterioration of its ampacity.

Figure 6 portrays the impact of air temperature on ampacity. As can be observed, there is a strong correlation between the weakening in ampacity and the rise in air temperature. It is also noticed that the relation curve appears to a line with fixed slope. This leads to use correction factors in high accurate during installation processes.

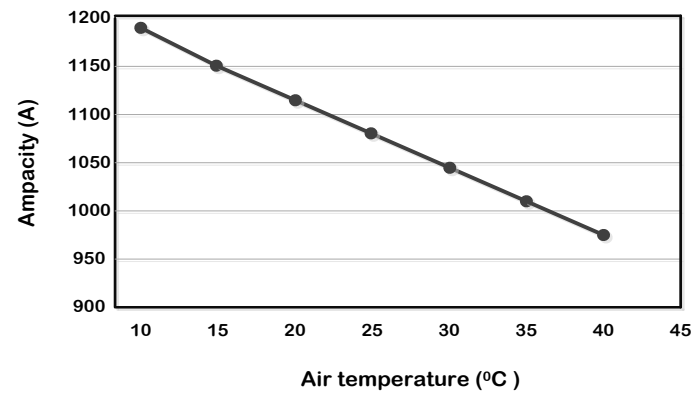

Figure 6. The influence of air temperature on ampacity

\subsection{Investigation on the influence of burial depth}

The burial depth also determines the thermal resistance of soil surrounding the cable. The deeper cable is buried the lower with its capacity before carrying current and this is as shown in Figure 7.

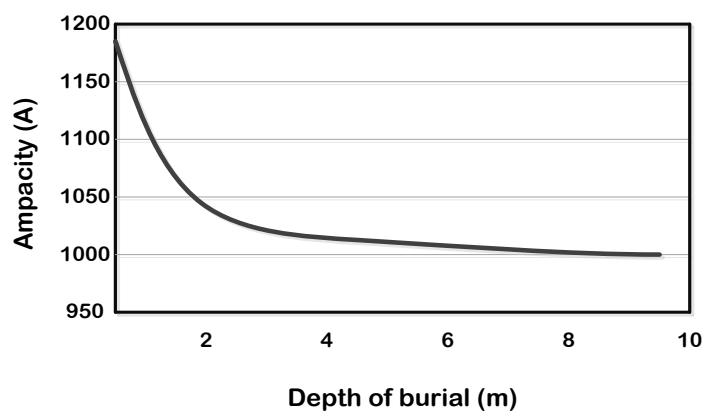

Figure 7. The correlation between ampacity and burial depth 
As portrayed in Figure 7, the current carrying capacity of the cable is diminished progressively with increasing in the depth of burial. It can be observed that the more deeply buried cables exert a significant influence over the cable ampacity ratings. Also apparent is the fact that the rate of cable ampacity alterations accelerates as the distance between the cable and the surface of the earth is reduced. This also leads to use high accurate de-rating factors through design.

\section{CONCLUSION}

A model was constructed to scrutinize the cable temperature distribution capacity and the influence of environmental issues on ampacity. The linear interpolation method together with the study model was employed to examine the factors influencing the current carrying capacity of an underground cable. A $33 \mathrm{kV}$ cable was decided on for this purpose. The results attained through this endeavour revealed that soil thermal conductivity and environmental temperatures significantly influence the current carrying capacity of a cable. While an elevation in soil thermal conductivity raised the cable current carrying capacity, the rise in environmental temperature diminished it linearly.

The results from this investigation also revealed that the ampacity of a cable decreases as the depth of cable burial increases. A notable outcome from this endeavour is the revelation that the critical temperature of wet soil leans more towards $550 \mathrm{C}$ than the $500 \mathrm{C}$ quoted by the IEC.

\section{ACKNOWLEDGEMENTS}

The author would like to thank the support that submitted by the University of Kerbala and the Iraqi Ministry of higher education and scientific research (Iraq).

\section{REFERENCES}

[1] Zhao Jianhua, et al., "Surface Temperature Field Based Online Diagnoses Study for Power Cable's Conductor Temperature," Proceedings of the CSEE, 11rd ed., vol. 19. pp. 52-54, 1999.

[2] GEORGE J. Anders. "Ration of electric power cables, ampacity computation for transmission, distribution, and industrial application," IEEE Press, 1997.

[3] FAN Chunli, et al., "Study on Quantitative Methods of Inspection and Breakage Diagnoses of High Voltage Line and Cable by Thermography," Proceedings of the CSEE, 18rd ed., vol.25. 2005, pp. 162-166.

[4] LIANG Yongchun, LI Yanmu, LI Yanming, CHAI Jinai, Wang Zhenggang, et al, "Calculation of the Static Temperature Field of Underground Cables Using Heat Charge Simulation Method," Proceedings of the CSEE, 16rd ed., vol. 28. 2008, pp. 129-134.

[5] P.Vaucheret, et al., "Ampacity Derating Factors for Cables Buried in Short Segments of Conduit," IEEE Transactions on Power Delivery, 2rd ed., vol. 20. 2005, pp. 560-565.

[6] Hanna M A, et al., "Thermal analysis of power cable in multi-layeredsoil-Part2: Practical Considerations," IEEE Transactions on Power Delivery, 3rd ed., vol.8. 1993, pp. 772-777.

[7] Vaucheret P, Hartlein R A, and Black W Z, "Ampacity Derating Factors for Cables in Short Segment of Conduit," IEEE Transactions on Power Delivery, 2rd ed., vol. 20, pp.1-6, 2005.

[8] Miyagi D, Wakatsuki T, and Takahashi N, "3-D Finite Element Analysis of Current Distribution in Hts Power Cable taking account of E-J Power Caw Characteristic," IEEE Transactions on Magnetics, 2rd ed., vol. 40, pp. 908-1001, 2004.

[9] LIANG Yongchun, et al., "A New Method to Calculate the Steady-State Temperature Field and Ampacity of Underground Cable System," Transactions of China Electrotechnical Society, 8rd ed., vol. 22, pp. 185-189, 2007.

[10] CAO Huiling, et al., "Numerical computation of temperature distribution of underground cables and soil with combinatorial coordinates," Transactions of China Electrotechnical Society, 3rd ed., vol. 18, pp. 59-63, 2003.

[11] FU Chenzhao, JIShengchang, and WANG Shishan, "A Study of Transient Thermal Circuit Model for the Cable Transformer Coil Based on Finite Element Method," Transactions of China Electrotechnical Society, 2rd ed., vol. 18 , pp. 77-82, 2003.

[12] IEC 60287-1. Calculation of the Current Rating-Part 1: Current Rating Equations (100\% Load Factor) and Calculation of Losses. 2001.

[13] IEC 60287-2. Calculation of the Current Rating-Part 2: Thermal Resistance. 2001.

[14] IEC 60287-3. Calculation of the Current Rating-Part 3: Sections on Operating Conditions. 1999.

[15] TAO Wenquan, Numerical Heat Transfer. Xi'an Jiaotong University Press, 2001.

[16] F. Donazzi, E. Occhini, and A. Seppi, "Soil thermal and hydrological characteristics in designing underground cables," in Proc. Inst. Elect.Eng., Jun. 1979, vol. 126, no. 6.

[17] Anders, Rating of Electric Power Cables. New York: IEEE Press/ McGraw-Hill, 1998.

[18] J. G. Hartley and W. Z. Black, "Transient simultaneous heat and mass transfer in moist unsaturated soils", ASME Trans., vol. 103, pp. 376-382, May 1981. 


\section{BIOGRAPHY OF AUTHOR}

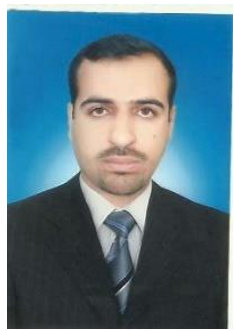

Mahmood Khalid Hadi, received the B.Sc. degree in electrical and electronic engineering from the University of Babylon, Babylon, Iraq, in 2005. The M.Sc. degree in electrical power engineering from the Universiti Putra Malaysia (UPM), Serdang, Malaysia, in 2017. Currently, he is an Assistant Lecturer and researcher at the Department of Electrical and Electronic Engineering, Faculty of Engineering, University of Karbala, Iraq. He also practices as an electrical engineer in electrical services installation works. His areas of research interest include, Power Engineering, Control Engineering, simulation, and design of power systems. 